\title{
PIBID UM CONTRIBUTO PARA O (DES) ENCANTAMENTO DO LICENCIANDO EM GEOGRAFIA DO IFRN - UM ESTUDO DE CASO
}

\author{
L. R. Miranda ${ }^{1}$ e I. C. Viana ${ }^{2}$ \\ ${ }^{1}$ Professor do Instituto Federal do Rio Grande do Norte - Doutorando em Ciências da Educação \\ ${ }^{2}$ Professora Doutora do Instituto de Educação da UMINHO/Braga/Portugal \\ E-mail: levi.miranda@ifrn.edu.br ${ }^{1}$, icviana@ie.uminho.pt ${ }^{2}$
}

Artigo submetido em outubro/2013 e aceito em outubro/2013

\section{RESUMO}

O presente trabalho tem por objetivo divulgar uma pesquisa, no âmbito do doutoramento, que destaca, essencialmente, analisar a contribuição que tem o Programa Institucional de Bolsa de Iniciação à Docência (PIBID), na decisão pessoal do licenciando em geografia do IFRN, sobre seu encantamento para ser professor. Pretende-se realizar uma pesquisa de cariz qualitativo, compreensiva, explorando ideias de vários autores que estudam esta problemática de investigação, analisando documentos que informam a política de formação de professores no Brasil e inquirindo intervenientes diretos neste processo. Através da iniciação à prática docente, o aluno-professor, terá condições para fazer uma reflexão sobre a sua futura atuação profissional. O PIBID, programa do Ministério da Educação, tem como finalidade antecipar o vínculo entre os licenciandos, a sala de aula e os ambientes escolares na rede pública de educação formal, articulando o ensino superior, a escola e os sistemas de educação. Perspectiva-se que este programa possa vir a acrescentar algumas estratégias de aprendizagem inovadoras nas aulas de geografia, articuladas com as táticas educacionais, formas de fazer, já praticadas pelos professores desta ciência geográfica. Atualmente, na área do subprojeto da licenciatura em Geografia, o PIBID tem a sua atuação em oito escolas da rede estadual de educação básica, com a participação de 42 bolsistas. Desta forma, é-lhe proporcionada a oportunidade de uma tomada de decisão pessoal consciente e refletida sobre o ato de ensinar, assumindo e se encantando, realmente, com sua futura profissão e desenvolvimento profissional.

PALAVRAS-CHAVE: Iniciação a Docência, Encantamento Com A Profissão, Educação Básica.

\section{A CONTRIBUTION TO THE PIBID (DES) ENCHANTMENT IN THE GEOGRAPHY OF LICENSING IFRN - A CASE STUDY}

\section{ABSTRACT}

This paper aims to disseminate research within the PhD, which focuses essentially on analyzing the contribution has the Institutional Program Initiation Scholarship to Teaching (PIBID), the decision of the licensing staff in geography IFRN on your enchantment to be a teacher. We intend to conduct a search of a qualitative nature, understanding, exploring ideas of several authors who study this problem research, analyzing the policy documents that inform teacher training in Brazil and inquiring direct stakeholders in this process. Through initiation into teaching practice, the student-teacher, will be able to reflect on their future professional practice. The PIBID, program of the Ministry of Education, aims to anticipate the link between the licensees, the classroom and school environments in the public formal education, linking higher education, schools and education systems. It is expected that this program is likely to add some innovative learning strategies in geography lessons, articulated with the educational tactics, ways of doing, as practiced by teachers in this geographical science. Currently, the area of the subproject's degree in Geography, the PIBID has its operations in eight schools of the state of basic education, with the participation of 42 scholars. This way, you are afforded the opportunity of a personal decision-making conscious and reflected on the act of teaching, taking and charming, really, with their future profession and professional development.

KEYWORDS: Initiation To Teaching, Charming With The Profession, Basic Education. 


\section{PIBID UM CONTRIBUTO PARA O (DES) ENCANTAMENTO DO LICENCIANDO EM GEOGRAFIA DO IFRN - UM ESTUDO DE CASO}

\section{INTRODUÇÃO}

O presente artigo propõe divulgar uma pesquisa em curso, cujo objetivo essencial é analisar a contribuição do Programa Institucional de Bolsa de Iniciação à Docência (PIBID), na decisão pessoal do licenciando em geografia do IFRN, sobre seu encantamento para ser professor, pois, através da iniciação à prática docente, este aluno-professor terá condições de fazer uma reflexão sobre o seu futuro profissional. O Programa tem como um dos seus objetivos centrais o fomento da formação inicial dos estudantes de licenciatura através de práticas de iniciação à docência, assumindo fundamental importância no estabelecimento da relação entre a teoria e a prática, possibilitando ainda, identificar as potencialidades e fragilidades do programa de iniciação à docência para o futuro profissional da geografia.

O que motiva esta pesquisa é uma reflexão em torno de como o PIBID poderá contribuir para que os futuros professores de geografia do IFRN possam ser inseridos no mundo do trabalho, promovendo, assim, o conhecimento e a intervenção na realidade escolar, seu futuro campo de atuação como docente. Pois é do nosso conhecimento que na busca da articulação de atividades de pesquisa, extensão e ensino, o programa PIBID desenvolve atividades didáticopedagógicas. Esta busca contribuirá para a formação docente dos alunos que cursam a Licenciatura em Geografia, ao mesmo tempo em que promove o diálogo entre a Instituição e as escolas públicas, buscando oferecer alternativas de melhoria das condições de ensino da Geografia das escolas públicas de Educação Básica. Nesta direção, este programa ensejará ao licenciando, após o conhecimento do seu futuro campo de ação profissional, a deliberação pessoal sobre a sua inserção na profissão e a sua formação como docente.

Constitui ainda referência essencial para a concretização desse trabalho acadêmico, o nosso interesse pessoal pelo tema em estudo, devido ao fato de estarmos assumindo, no momento atual, a coordenação do subprojeto de Licenciatura em Geografia do PIBID, ano 2011, do Campus Central do IFRN. Com este intuito, desenvolvemos esta proposta começando por contextualizá-la no âmbito da política do Ministério da Educação, seguindo-se uma problematização da sua pertinência no encantamento dos futuros professores com a profissão professor, terminando com uma nota final em jeito de síntese integrada da problemática em estudo.

\section{AÇÕES DO PROGRAMA DE INICIAÇÃO A DOCÊNCIA}

O programa PIBID - criado em 2007 e iniciado em 2008 - pelo Ministério da Educação, junto a CAPES-Fundação coordenação de Aperfeiçoamento de Pessoal de Nível Superior, e Diretoria de Educação Básica-DEB, através da Coordenção-geral de desenvolvimento de conteúdos Curriculares e Modelos Experimentais, tem como objetivo antecipar o vínculo entre os licenciandos, a sala de aula e os ambientes escolares na rede pública de educação formal, articulando assim o ensino superior, a escola e os sistemas de educação. Desta forma, busca-se promover a formação docente necessária para a atuação na Educação Básica pública, fomentando a iniciação à docência. 
O PIBID é um programa que se desenvolve através da concessão de bolsas de iniciação à docência para os alunos, futuros professores, que cursam regularmente uma licenciatura em instituições públicas de Ensino Superior, como também para os coordenadores e supervisores responsáveis pela execução de programa. $O$ intuito principal é induzir e fomentar a formação inicial e continuada de profissionais do magistério, com base na Lei de no 11.502, datada em 11 de julho de 2007, seguindo as diretrizes do Plano de Metas Compromisso Todos pela Educação, implementado pelo Decreto no 6.094, de abril de 2007 e aos princípios estabelecidos na Política Nacional de Formação de Profissionais do Magistério da Educação Básica, ainda com base no Decreto 6.755, de 29 de janeiro de 2009 e na Lei no 11.947, de 16 de junho de 2009, art. 31 . 0 Programa desenvolve-se através de convênios estabelecidos com instituições do ensino superior:

\begin{abstract}
O Programa efetiva-se por meio do estabelecimento de convênios entre as instituições de educação superior, que forneçam cursos de licenciatura, e as redes de educação básica pública com vistas a promover a atuação dos licenciandos em formação inicial nas práticas pedagógicas dessas escolas. Celebrado o convênio, a CAPES concede bolsas para professores coordenadores, docentes locados na escola de educação básica e os licenciandos selecionados. Os professores-coordenadores correspondem aos docentes ligados às instituições de educação superior e tem como responsabilidade o acompanhamento do planejamento, a organização e a execução das atividades previstas, além do auxílio aos estudantes bolsistas no suprimento das dificuldades que encontrarem no exercer de suas tarefas. Já o docente em exercício na escola de educação básica, participante do projeto, atua supervisionando as atividades dos bolsistas; ele é a ponte entre a universidade e a escola básica. (MIRANDA ET AL,2012, p 2).
\end{abstract}

Segundo a mesma fonte, atualmente, no Brasil o PIBID é desenvolvido em 195 Instituições de Educação Superior de todo o país, que desenvolvem 288 projetos de iniciação à docência em aproximadamente 4 mil escolas públicas de educação básica. Com a expansão através do edital de 2012, o número de bolsas concedidas atingiu 49.321, representando assim um crescimento de mais de $80 \%$ em relação a 2011. No Rio Grande do Norte o Programa é desenvolvido por quatro instituições de Educação Superior, são elas: Universidade federal do Rio Grande do Norte-UFRN; Universidade Federal Rural do semi-árido - UFERSA; Instituto Federal de Educação, Ciência e Tecnologia do Rio Grande do Norte - IFRN e Universidade Estadual do Rio Grande do NorteUERN. No IFRN o programa atual, PIBID 2011, conta com a participação de 291 estudantes bolsistas distribuidos pelas licenciaturas da Instituição. No campus central estão locadas as licenciaturas de Geografia( 42 bolsistas); Espanhol(35 bolsistas); Física( 35 bolsistas) e Matemática( 35 bolsistas) e, nos demais campus, temos as licenciaturas de Química, no campus de Pau dos Ferros (20 bolsistas) e no campus de Currais Novos( 32 bolsistas); a licenciatura de Informática, no campus de Ipanguaçu (10 bolsistas) e Zona Norte/Natal( 12 bolsistas); Matemática( 15 bolsistas) e Física( 35 bolsistas), no campus de Santa Cruz e no campus de Educação a Distância - EAD, a licenciatura de Espanhol ( 20 bolsistas).

$\mathrm{Na}$ área do subprojeto da licenciatura em Geografia, o PIBID tem a sua atuação em oito escolas da rede estadual de educação básica, tendo o apoio de um professor lotado na escola com a função de supervisionar as atividades dos bolsistas de iniciação à docência. São as seguintes escolas públicas participantes do programa: Escola Estadual Professor Castro Alves, Escola Estadual Professor Francisco Ivo Cavalcanti, Escola Estadual Professora Josefa Sampaio, Escola Estadual Professor Antônio Pinto de Medeiros, Escola Estadual Nestor Lima, Escola Estadual Walter Pereira, Escola Estadual José Fernandes Machado e Escola Estadual Ferreira 
Itajubá. Estando todas essas escolas localizadas na cidade do Natal e vinculadas à Secretaria Estadual de Educação do RN.

Ressalta-se que as escolas da rede estadual de ensino do RN apresentam baixas taxas no rendimento da aprendizagem de seus alunos, tanto no ensino fundamental quanto no ensino médio, fato este comprovado com base nos resultados do Índice de Desenvolvimento da Educação Básica (IDEB). Este vetor mede a qualidade do ensino das escolas públicas de educação básica no país, posicionando-se assim o Estado abaixo da média nacional, fato este que reforça a importância de programas de reforço escolar tal como o PIBID. Pois, o mesmo tem como principais objetivos elevar a qualidade da formação inicial nos cursos de licenciatura e inserir os licenciandos no cotidiano de escolas da rede pública de educação, oportunizando-os à participação em experiências didático-metodológicas, tecnológicas e práticas docentes, contribuindo, desta forma, para a articulação da teoria com a prática, essencial na formação dos docentes, elevando a qualidade das ações acadêmicas nos cursos de licenciatura.

O PIBID, além de oportunizar ao licenciando de geografia a decisão em sua formação profissional, pretende-se que este programa possa vir a acrescentar algumas estratégias inovadoras de aprendizagem nas aulas de geografia, articuladas com as táticas educacionais já praticadas pelos professores desta ciência geográfica. Para o sucesso da execução do programa é essencial que a comunidade escolar seja sensibilizada sobre importância do saldo positivo advindo da implantação deste subsídio educacional, que, por outro lado, pressupõe-se que seja uma das primeiras oportunidades de contato do licenciado em geografia com a sala de aula, oportunizando decidir sobre a sua escolha profissional.

Neste sentido, as bases teóricas do programa atual afirmam ser importante o envolvimento da direção, da equipe pedagógica, dos professores, dos servidores e dos supervisores das escolas parceiras, tornando-se imprescindíveis para a viabilidade da ação. Com o objetivo maior de contribuir para a superação das dificuldades encontradas no processo ensino-aprendizagem, destacando soluções e, sobretudo, buscar implementá-las através de ações didático-pedagógicas. O programa também evidencia a necessidade da participação destes integrantes do plano de trabalho nas reuniões para a socialização das dificuldades das atividades e das ações, facilitando o trabalho que deverá ser coletivo e interdisciplinar, uma vez que além as disciplinas que participam do Projeto institucional do PIBID, existem todas as outras da grade curricular que podem ser trabalhadas de forma interdisciplinar.

Portanto, o programa tem a expectativa de contribuir para a valorização da escola pública, enquanto espaço de formação inicial aluno-docente de Geografia e de formação continuada dos professores que exercem sua docência nas escolas envolvidas diretamente nesse programa. Desta forma, procurando a consonância com as atuais orientações curriculares para a Educação Básica, e resguardando a autonomia do professor que atua em sala de aula, pensando em alternativas para o ensino da Geografia, com a função de facilitar e dinamizar o processo de ensino-aprendizado. Nesse sentido, a proposta busca também contribuir para que os alunos venham a participar do Exame Nacional do Ensino Médio (ENEM), melhorando o ensino e o desempenho com relação ao Índice de Desenvolvimento da Educação Básica (IDEB) no País.

Neste sentido, as atividades previstas neste programa deverão acontecer por meio da realização de aulas de reforço, oficinas, mini cursos, leituras geográficas, estudo do meio, 
envolvendo diferentes ambientes intra e extra-escolar, promovendo de forma sistemática uma interação entre os demais componentes curriculares.

\section{O PIBID COMO PROPULSOR NO DESPERTAR DO ENCANTAMENTO PARA A DOCÊNCIA}

O desenvolvimento profissional dos professores se dá inicialmente através da sua formação na academia, mas não podemos descartar a importância fundamental que tem a sua prática docente no campo de atuação, ou seja nas escolas. O PIBID age como um fator determinante na decisão do licenciando em reconhecer a docência como escolha da sua identidade profissional, pois estabelece logo no início da formação acadêmica o contato direto com o magistério, fazendo assim um elo entre a teoria e a prática . Num estudo levado a efeito pelas universidades do Minho e de Nottingham (FLORES, DAY e VIANA, 2007, p.8) no âmbito de questões relacionadas com mudanças na política curricular, no profissionalismo e na(s) identidade(s) dos professores, são evidenciados resultados que destacam importâncias diversas, tais como "(...) a importância atribuída à aprendizagem contínua e às culturas colaborativas, a relevância do trabalho de projeto e um entendimento mais amplo dos papéis da escola e dos professores (...)", para interagirem com perfis, interesses e prioridades dos alunos do século XXI (VIANA, 2013). Responder a estes interesses e prioridades, a sua compreensão está relacionada com a importante articulação desses interesses e prioridades com a interdependência do conhecimento teórico e prático.

O sentido de identidade dos professores é trabalhado por vários autores, tal como refere kelchtermans (2009), assumido como papel essencial na compreensão do seu agir profissional. A descoberta da significação pessoal e social da sua profissão é de grande valia para o futuro alunoprofessor, pois é necessário conhecer os valores, as práticas, as angústias e os anseios advindos da construção de sua vida profissional na reafirmação do ser professor, assim nos fala Pimenta (2005, p.19):

\footnotetext{
(...) Uma identidade profissional se constrói, pois, a partir da significação social da profissão; da revisão constante dos significados sociais da profissão; da revisão das tradições. Mas também da reafirmação de práticas consagradas culturalmente e que permanecem significativas. Práticas que resistem a inovações porque prenhes de saberes válido às necessidades da realidade. Do confronto entre as teorias e as práticas, da análise sistemática das práticas à luz das teorias existentes, da construção de novas teorias. Constrói-se também pelo significado que cada professor, enquanto ator e autor, confere à atividade docente no seu cotidiano a partir de seus valores, de seu modo de situar-se no mundo, de sua história de vida, de suas representações, de seus saberes, de suas angústias e anseios, do sentido que tem em sua vida o ser professor. Assim como a partir de sua rede de relações com outros professores, nas escolas, nos sindicatos e em outros agrupamentos.
}

O ser professor numa sociedade que pouco tem valorizado esta formação profissional, por si já se constitui num grande desafio vivencial para o licenciando no início da sua vida acadêmica, mas o primeiro obstáculo a ser superado é o enfrentamento da realidade contidiana da escola pública. A insegurança pode conduzir esse aprendiz de professor a desapontar-se ou a deslumbrar-se com o cenário escolar que já conhecia em um passado recente, mas desta vez 
numa nova condição na comunidade escolar, atuando como docente. Assim Cavalcanti (2011, apud MIRANDA et al, 2012,p. 3), nos afirma que:

\begin{abstract}
(...)frequentemente se relaciona com futuros professores, em período de estágio, tomados por um clima de medo e insegurança em relação ao exercício da profissão. No bojo dessa problemática destacam-se a dificuldade encontrada pelos licenciandos em desenvolver atividades que busquem motivar os alunos e o desafio de fazer com que estes respeitem o professor e contribuam para o bom andamento das aulas. Tal cenário se agrava quando se considera que a prática de estágio, geralmente, ocorre nos anos finais dos cursos de formação de professores. De uma hora para outra, os licenciandos deparam-se com uma realidade pouco vivenciada, até mesmo desconhecida, durante sua trajetória no curso superior; muitos se espantam chegando até mesmo a desistir da carreira.
\end{abstract}

A expectativa do licenciando diz respeito a apreensão pela falta da prática, e do domínio: disciplinar na sala de aula, do conteúdo, da metodologia, dos diversos recursos didáticos, do conhecimento pedagógico geral, do currículo e programas, dos valores educativos, seus fins e propósitos. Também se considera relativa à sua posição cidadã diante de um novo momento em sua vida, levando-os muitas das vezes a um certo desespero no fazer pedagógico. Contudo, ao longo do exercício docente, através da observação, participação e da regência é que obtém condições para refletir a futura profissão professor, tal como refere Januário (2008, p.2):

\footnotetext{
(...) [o] licenciando poderá refletir sobre e vislumbrar futuras ações pedagógicas. Ao iniciar uma licenciatura, muitas vezes nos deparamos com a insegurança e o receio de não conseguirmos desenvolver um bom trabalho em sala de aula. Alguns temem não conseguir dominar a classe, outros se preocupam em não saber todo o conteúdo que julgam necessário, uns questionam-se quanto ao método que adotarão e outros, ainda, anseiam por ministrar aulas. Há ainda uns que se quer pensam em lecionar. Porém, com o passar do tempo, os licenciandos passam por uma transformação desses sentimentos e começam a se ver enquanto professores. Essas mudanças começam, possivelmente, a partir das conversas com os colegas, das leituras e discussões em sala de aula, sob a orientação de um professor, ou dos relatos dos colegas que, talvez, já lecionem.
}

Neste momento de trocas de ideias reflexivas com os demais colegas sobre suas experiências não tanto satisfatórias, como as atividades desenvolvidas de forma positiva o licenciando pode, a partir deste momento, despertar para o encantamento diante da sua identidade profissional, com o orgulho de ser um cidadão corresponsabilizado com os seus alunos e com a sociedade na qual está inserido.

Ao futuro professor evidencia-se significativo a consciência de que o prazer em lecionar se poderá apoiar no fato do mestre agir de forma carinhosa, transformadora e acolhedora. É por demais gratificante e estimulante exercer o magistério como profissão, pois, a sedução do ato de educar, evoca o sentido de aceitação da opinião do discente, respeitando e valorizando suas histórias e experiências de vida. O aluno-professor beneficia se acreditar que a sua disponibilidade permite a capacidade do fazer pedagógico com segurança, numa dinâmica de refletir-aprender-experimentar-ensinar de forma prazerosa e gratificante.

O licenciando em Geografia, ou de qualquer outra licenciatura, quando da sua iniciação à docência, enfrenta o desafio da dualidade do ser-educando para ser-educador, sobre este tema Freire (1987, p.78-79) ameniza a provocação quando nos afirma: 
(...) o educador já não é o que apenas educa, mas o que, enquanto educa, é educado, em diálogo com o educando que, ao ser educado, também educa. Ambos, assim, se tornam sujeitos do processo em que crescem juntos e em que, os 'argumentos de autoridade' já não valem. Em que, para ser-se, funcionalmente, autoridade, se necessita de estar sendo com as liberdades e não contra elas (...). Já que agora ninguém educa ninguém, como tampouco ninguém se educa a se mesmo: os homens se educam em comunhão mediatizados pelo mundo.

Nesta perspectiva de quem ensina também aprende, o mesmo autor (idem, p.23) completa seu pensamento assegurando não haver docência sem discência, resultando, da interação subjacente, uma aprendizagem simultânea:

(...) não há docência sem discência, as duas se explicam e seus sujeitos apesar das diferenças que os conotam, não se reduzem à condição de objeto, um do outro. Quem ensina aprende ao ensinar e quem aprende ensina ao aprender.

A ampliar este raciocínio, Delors (2003, p. 97-98), a explorar o que designa de missão da educação, destaca o seguinte:

(...) a educação tem por missão, por um lado, transmitir conhecimentos sobre a diversidade da espécie humana e, por outro levar as pessoas a tomar consciência das semelhanças e da interdependência entre os seres humanos do planeta. Desde tenra idade a escola deve, pois, aproveitar todas as ocasiões para esta dupla aprendizagem (...) passando a descoberta do outro, necessariamente, pela descoberta de si mesmo (...). 0 confronto através do diálogo e da troca de argumentos é um dos instrumentos indispensáveis à educação do século XXI

A nossa idéia de induzir a prática docente através da ação do PIBID aprofunda-se no pressuposto de que os conhecimentos, perspectivas e experiências dos futuros professores de Geografia estão relacionados com a sua iniciação à prática de ensino. Desta forma, é imprescindível perceber o elo entre as práticas dos docentes nos domínios do ensino e as aprendizagens desenvolvidas pelos seus estudantes.

Neste sentido, Traversini; Buaes (2009) evidenciam o seguinte:

(....) ao estudar metodologias de ensino, as entendemos como práticas pedagógicas operacionalizadas por meio de conjuntos de atividades escolares propostas pelos professores com vistas a alcançar a aprendizagem de determinados conhecimentos, valores e comportamentos. significadas pela linguagem, as atividades escolares são classificadas como geradoras ou não de aprendizagem vinculadas a diferentes discursos pedagógicos - conhecidos nos meios educacionais como tradicionais, tecnicistas e construtivistas, como mostra diaz (1998) - dominantes em determinadas épocas, bem como relacionadas aos efeitos das experiências vivenciadas pelos professores e alunos como sujeitos e assujeitados pelas verdades instituídas nesses discursos pedagógicos.

Este entendimento destaca que o grande desafio das instituições de ensino superior na exploração sistemática da formação dos seus educadores e na problematização continuada do desempenho destes na prática educativa da educação básica, tem o intuito de contribuir para que os jovens aprendizes exerçam sua cidadania plena numa sociedade repleta de diversidades, pois, segundo Cunha (2001, apud SOUZA \& DIAS, 2011, p.87), de um modo geral, a formação de professores assume destaque pelo desfasamento existente entre a formação inicial e os contextos reais de trabalho, como referem, "(...) tem sido abordada tomando-se como foco 
principal o problema da defasagem existente entre a formação oferecida pelas instituições de ensino superior, através dos cursos de licenciaturas e a realidade da atividade prática existente".

Este mesmo autor (CUNHA,2001, p.104) levanta um questionamento sobre a adequação deste cursos de licenciatura em relação ao exercicio das atividades profisionais, assim ele nos fala:

os Cursos de Licenciatura não se definem apenas pelo currículo explícito que adotam nem pelas ênfases em conteúdos específicos que ministram. Muito mais do que isto, eles revelam visões de conhecimento, de educação e de prática pedagógica. $E$ tudo indica que estes valores presentes e manifestos na prática cotidiana são elementos de formação muito mais poderosos do que os conteúdos desenvolvidos. As tradicionais dicotomias entre sujeito e objeto, conteúdo específico e matérias pedagógicas, saber e saber fazer, ciências naturais e ciências sociais, teoria e prática, mesmo que negadas no campo discursivo dos docentes, revelam-se com intensidade assustadora na formação dos licenciandos, porque vão construindo os constructos imaginários sobre os quais sua futura docência se alicerçará.

A literatura sobre a importância do ensino da geografia, como também da iniciação à docência é bastante extensa abordando uma diversidade de temas, tais como: a problematização das aulas de geografia baseadas nos conteúdos dos livros didáticos (KAERCHER, 2003), o papel da escola e do ensino da geografia que atuam, simultaneamente, como instrumentos de reprodução do sistema e de libertação (VESENTINI, 2003) e tantas outras temáticas são resultantes de trabalhos realizados pelos mais diversos estudiosos da ciência geográfica. Dentre as mais variadas temáticas, destacamos o papel social desempenhado pelo professor diante de um mundo em constantes transformações, assim evidenciado por Benaduce (2009, p.1):

(....) A responsabilidade social do professor de Geografia, perante a velocidade com que os fenômenos ocorrem neste período pós-moderno suplanta rapidamente os dados contidos nos livros didáticos. Assim o professor de Geografia necessita conjugar os dados contidos nestes livros com as dinâmicas vivenciadas pela sociedade. Esta atitude reporta a uma outra que de uma forma ou outra está inserida naquilo que tem sido uma preocupação constante dos professores de Geografia: Quais são os aspectos limitadores da prática pedagógica em Geografia? O que é possível construir na disciplina de Geografia? Respostas para tais indagações certamente devem ser contextualizadas mediante o papel que a educação desempenha no mundo contemporâneo.

Segundo esta perpspectiva, cabe ao docente iniciante assumir o papel de sujeito facilitador do processo de aprendizagem, desenvolver uma prática dinâmica e interativa que permita ao educando do século XXI refletir sobre as mais variadas teses geográficas de forma ativa, reflexiva, investigativa, problematizadora e propositiva, cultivando o prazer na sua formação acadêmica, despertando um encantamento pelo ato de educar. 


\section{CONSIDERAÇÕES FINAIS}

Segundo os autores invocados e considerando a nossa própria experiência como professores, formadores e coordenadores do programa de iniciação à docência, na licenciatura de geografia, parece que, os futuros professores desprovidos de experiências na docência, têm evidenciado dificuldades em assumir a sala de aula, tendo insegurança nas decisões e atitudes característicos do processo pedagógico. Pela sua dinâmica, apresenta fatos novos no desenvolvimento cotidiano, desde o planejamento das atividades como também a preparação para a resolução dos problemas disciplinares surgidos nas diversas situações do ambiente escolar. Nesta perspectiva, evidencia-se necessário que os futuros docentes aprendam a adaptarse à realidade de ensino e a reflitir sobre o seu futuro desenvolvimento profissional, trabalhando a resiliência na profissão professor.

Espera-se que os resultados da investigação em curso constituam um contributo para problematizar a formação inicial de professores no contexto da política de formação de professores no Brasil e permitam melhor compreender a importância do programa de iniciação à docência (PIBID) na prática docente do aluno da licenciatura em Geografia do IFRN. Neste sentido, poderão facilitar e enriquecer a reflexão sobre a política e os contextos de formação e refletir conceitos teóricos trabalhados em sala de aula na formação acadêmica geográfica e sua relação com a prática pedagógica no ensino médio da rede oficial de ensino da cidade de Natal/RN. É nossa convicção que os resultados desta prática docente podem ser relevantes para oportunizar a decisão pessoal do licenciando em assumir e envolver-se, realmente, com a sua futura formação profissional, como também para a reformulação e melhoria do programa do curso de Geografia do IFRN, minimizando, antecipadamente, as dificuldades encontradas pelos licenciados em Geografia na iniciação da sua prática como professor.

Assim sendo, o PIBID serve como um contributo ao antecipar, logo no início do curso, o convívio do licenciando de geografia do IFRN com a realidade que se apresenta no ensino público, podendo, no transcorrer dos anos de formação acadêmica, o estudante bolsista do programa desenvolver uma postura docente mais firme e criar estratégias de ensino com mais segurança e confiança, vivenciando possíveis problemas e dilemas surgidos no ambiente da prática educativa/docente.

Por último, gostaríamos de afirmar que a experiência docente antecipada vai permitir uma formação do licenciando de forma mais qualificada no processo de ensino e aprendizagem, contribuindo para o envolvimento com a profissão professor e para despertar o encantamento com a formação profissional por que optou. Ainda, pensamos poder criar incentivo para enfrentar os desafios advindos da prática docente, numa perspectiva de valorizar a inclusão social através da escola, acreditando ser através da educação de qualidade que podemos almejar uma sociedade mais igualitária e democrática, permitindo a formação de cidadãos conscientes, autónomos, críticos e participativos. 


\section{REFERÊNCIAS}

1. BENADUCE, G.M.C. O ensino de Geografia nas escolas de ensino médio. obtido em http:// egal2009.easyplanners.info (artigo 3119). acessado em 18 de junho de 2012.

2. BRASIL. Decreto no 7.219, de 24 de junho de 2010. Dispõe sobre o Programa Institucional de Bolsas de Iniciação à Docência - PIBID e da outras providências. Diário Oficial da União, $\begin{array}{lllll}\text { Brasília, } & 25 & \text { jun. } & 2010 . & \text { Disponível }\end{array}$ http://www.capes.gov.br/images/stories/download/diversos/DecretoPIBID_240610.pdf. Acesso em: 23 mar. 2012.

3. DELORS, J. Educação: um tesouro a descobrir.8 ed, São Paulo.Cortez; Brasília,DF: MEC: UNESCO. 2003.

4. FREIRE, P. .Pedagogia da autonomia: saberes necessários à prática educativa. 31ạ Ed. São Paulo: Paz e Terra. 1996.

5. FREIRE, P. Pedagogia do Oprimido. Rio de Janeiro: Paz e Terra. 1987.

6. JANUÁRIO, GILBERTO . 2008) O estágio supervisionado e suas contribuições para a prática pedagógica do professor. Disponível em http://www.educadores.diaadia.pr.gov.br/arquivos/File/2010/artigos_teses/MATEMATICA/A rtigo_Gilberto_06.pdf. Acesso em 21 de fev 2013.

7. KELCHTERMANS, G.. O compromisso profissional para além do contrato: autocompreensão, vulnerabilidade e reflexão dos professores. In FLORES, M. A. \& VEIGA SIMÃO, A. M. (orgs.). Aprendizagem e desenvolvimento profissional de professores. Mangual: Edições Pedago, 2009, pp. 61-98.

8. MIRANDA ET AL. . PIBID Geografia na escola estadual Antônio Pinto de Medeiros: contribuições para uma formação cidadã, ifrn.2012. Disponível em http://www2.ifrn.edu.br/ojs/index.php/HOLOS/article/view/889. Acesso em 21 fev. 2013.

9. PIMENTA, S.G . Formação de professores: identidade e saberes da docência. In: PIMENTA, Selam Garrido et al (orgs). Saberes pedagógicos e atividades docente. São Paulo: Cortez, 4 ed. 2005

10. SOUZA,R.F.V \& DIAS,F.E. Proposta de melhoria da formação de professores da educação básica através da iniciação a docência em um clube de ciências e cultura.2011 Obtido em http://www.cefetsp.br/edu/sertaozinho/revista/ ARTIGOS/volume1 numero7artigo7.pdf. Acessado em 12 de junho de 2012

11. TRAVERSINI, C. S. \& BUAES, C. S. . Como discursos dominantes nos espaços da educação atravessam práticas docentes? Revista Portuguesa de Educação. Braga. V. 22, N.2. 2009

12. VIANA, I. C. Desafios do século XXI às políticas curriculares e a formação de professores em Portugal. In OLIVEIRA, M. R. N. S. \& PACHECO, J. A. (orgs.). Currículo, Didática e Formação de Professores. Campinas: Papirus, 2013,pp. 97-130. 